Research Article

\section{Diagnosis of critical congenital heart defects in Iceland 2000-2014}

\author{
Hallfríður Kristinsdóttir ${ }^{1}$, Pórður Pórkelsson ${ }^{1,2}$, Hildur \\ Harðardóttir ${ }^{1,3}$ and Gylfi Óskarsson ${ }^{1,2 *}$ \\ ${ }^{1}$ University of Iceland, Iceland \\ ${ }^{2}$ Children's Hospital, Landspitali University Hospital, Reykjavík, Iceland \\ ${ }^{3}$ Department of Obstetrics and Gynecology, Landspitali University Hospital, Reykjavik, Iceland
}

\section{Abstract}

Critical congenital heart defects (CCHDs) are preferably diagnosed prenatally or soon after birth. Late diagnosis has been related to poorer prognosis. The aim of this study is to assess when CCHDs are diagnosed in Iceland and whether late diagnosis is a problem. All live born children in Iceland and foetuses diagnosed with CCHDs during the years 2000-2014 were included. CCHD was defined as a defect requiring intervention or causing death in the first year of life, or leading to abortion.

The total number of pre- and postnatal diagnosis of CCHDs was 188. Prenatal diagnosis was made in 69 of 188 (36.7\%). Of 69 diagnosed prenatally 33 were terminated due to CCHD. Of the 155 live born children with CCHD, $36(23.2 \%)$ had a prenatal diagnosis and $100(64.5 \%)$ were diagnosed shortly after birth, before discharge from birth facility. 19 children (12.3\%) were diagnosed late, that is after discharge from birth facility. Coarctation of the aorta was the most common CCHD diagnosed late (6/19).

Prenatal screening and newborn examination give good results in diagnosis of CCHDs in Iceland. Late diagnosis are relatively few, but both the number of prenatally diagnosed CCHDs and CCHDs diagnosed shortly after birth can be further improved.

\section{More Information}

*Address for Correspondence: Gylfí Óskarsson, Director of Pediatric Cardiology, Children's Hospital, Landspitali University Hospital, University of Iceland, Reykjavík, Iceland, Tel: +354-8255019; Email: gylfio@landspitali.is

\section{Submitted: 23 October 2019 \\ Approved: 01 November 2019 \\ Published: 04 November 2019}

How to cite this article: Kristinsdóttir $\mathrm{H}$, Pórkelsson P, Harðardóttir H, Óskarsson G. Diagnosis of critical congenital heart defects in Iceland 2000-2014. J Cardiol Cardiovasc Med. 2019; 4: 177-181.

DOI: dx.doi.org/10.29328/journal.jccm.1001062 ORCiD: orcid.org/0000-0002-7560949X

Copyright: (c) 2019 Óskarsson G, et al. This is an open access article distributed under the Creative Commons Attribution License, which permits unrestricted use, distribution, and reproduction in any medium, provided the original work is properly cited.

\section{Check for updates}

\section{Introduction}

The incidence of congenital heart defects in total is around $1 \%-1.7 \%$ [1-3]. About $10 \%$ of heart defects are critical, sometimes immediately life-threatening, and require early intervention (1-2.6 per 1000 live births) [4-8]. Early diagnosis of critical congenital heart defects (CCHDs), preferably prenatally or soon after birth, relates to a better outcome regarding survival and general prognosis [9-12].

Recent studies have shown that high proportion (13-30\%) of CCHDs is diagnosed late, that is after discharge from birth facility $[5-8,13,14]$. The defects that are most often missed are left outflow tract obstructions (LOTOs), such as coarctation of the aorta $(\mathrm{CoA})[7,8,14]$. In response, many countries have implemented new methods to detect heart defects in newborn screening programmes. Routine pulse oximetry (POX) combined with physical examination is the most popular and most studied method, showing increased sensitivity and good specificity in diagnosis of CCHDs [4,15-18]. Still, POX also commonly misses LOTOs, for example CoA $[4,15]$. Newborn screening in Iceland includes a physical examination before discharge from birth facility, and a repeated physical examination at the age of 5 days. POX had not been introduced as a part of newborn screening during the study period. The aim of this study is to asses when CCHDs are diagnosed in Iceland and whether late diagnosis is a problem.

\section{Materials and Methods}

We conducted a retrospective study on all live births and abortions in Iceland from 2000 to 2014 (both years included) and included all diagnosed with CCHD. CCHD was defined as a structural defect of the heart or great vessels leading to abortion, requiring intervention, by open surgery or with catheterization, or causing death in the first year of life. Excluded were children delivered preterm $(<38$ weeks gestation) with isolated patent ductus arteriosus.

Data on congenital heart disease diagnosis was collected from the National Hospital databases. Medical records of those with an ICD-10 diagnosis compatible with CCHD were reviewed 
to confirm a diagnosis of CCHD. Data on total live born children per year was obtained from the national birth registry and the general national registry. Data on follow-up was collected until and including January 2019. As this study was exclusively based on retrospective data collection no informed consent was needed and was not required by Landspitali National hospital bioethics committe. The study was performed according to national regulations and accepted by the Landspitali National hospital bioethics committe (3/2015).

Microsoft Office Excel 2007, R (version 3.1.2) and RStudio were used for statistical analysis, which was mostly descriptive. Chi-squared test was used for comparison of ratios and determined statistically significant if $p<0.05$.

\section{Results}

During the 15-year study period a total of 188 CCHDs were diagnosed pre- and postnatally. The incidence was 2.82 per 1000 live born children for the whole period. By dividing the study period in 5-year periods and comparing the incidence a significant reduction in incidence was found (Figure 1).

Prenatal diagnosis was made in 69 of 188 CCHDs or $36.7 \%$. In 33 cases the family chose to terminate the pregnancy due to a poor prognosis of the diagnosed CCHD. A high proportion of HLHS cases, 19/21 were diagnosed prenatally, but no prenatal diagnosis of simple transposition of the great arteries (TGA) was achieved (0/15). The prenatal diagnosis are shown in table 1 .

The total number of live born children with CCHD was 155 , an incidence of 2.33 per 1000 . The male:female ratio was 93:62 or 1.5:1. A CCHD had been diagnosed prenatally in 36 of 155 live born children. Further 100 children (64.5\%) were diagnosed before discharge home.

There were 19 children (12.3\%) discharged home without a diagnosis of CCHD (Table 2). If CCHDs that are very difficult to detect early such as ALCAPA and double aortic arch are excluded, the number can be reduced to 16 children or $10,5 \%$. 13 of 19 children had severe symptoms at diagnosis but late diagnosis did not cause any deaths. The most common CCHD

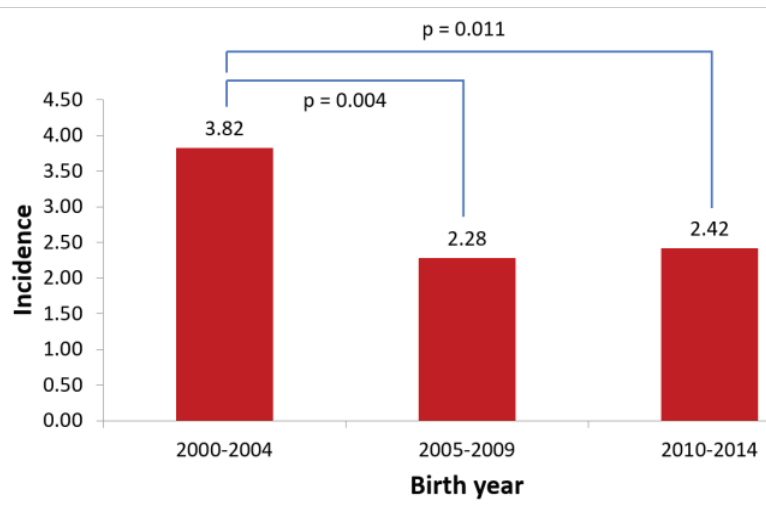

Figure 1: Comparison of incidence of CCHDs (including abortions) per 1000 live born in 5-year periods.

\begin{tabular}{|c|c|c|c|c|c|c|}
\hline \multirow[b]{2}{*}{ Heart defect } & \multicolumn{2}{|c|}{ Total } & \multicolumn{2}{|c|}{ Live born } & \multicolumn{2}{|c|}{ Aborted } \\
\hline & $\begin{array}{l}\text { Number } \\
(n=69)\end{array}$ & $\%$ & $\begin{array}{l}\text { Number } \\
(n=36)\end{array}$ & $\%$ & $\begin{array}{l}\text { Number } \\
(n=33)\end{array}$ & $\%$ \\
\hline HLHS & 19 & 27,5 & 1 & 2,8 & 18 & 54,5 \\
\hline Complicated & 11 & 15,9 & 8 & 22,2 & 3 & 9,1 \\
\hline CoA & 6 & 8,7 & 5 & 13,9 & 1 & 3,0 \\
\hline CoA & 3 & 4,3 & 3 & 8,3 & 0 & 0,0 \\
\hline CoA+VSD & 1 & 1,4 & 1 & 2,8 & 0 & 0,0 \\
\hline CoA+subas & 1 & 1,4 & 1 & 2,8 & 0 & 0,0 \\
\hline $\mathrm{IAA}+\mathrm{VSD}$ & 1 & 1,4 & 0 & 0,0 & 1 & 3,0 \\
\hline PA/IVS & 5 & 7,2 & 4 & 11,1 & 1 & 3,0 \\
\hline AVSD & 4 & 5,8 & 1 & 2,8 & 3 & 9,1 \\
\hline PA/VSD & 4 & 5,8 & 3 & 8,3 & 1 & 3,0 \\
\hline SV & 3 & 4,3 & 0 & 0,0 & 3 & 9,1 \\
\hline AS & 2 & 2,9 & 2 & 5,6 & 0 & 0,0 \\
\hline DORV & 2 & 2,9 & 2 & 5,6 & 0 & 0,0 \\
\hline Ebstein & 2 & 2,9 & 1 & 2,8 & 1 & 3,0 \\
\hline PS & 2 & 2,9 & 2 & 5,6 & 0 & 0,0 \\
\hline $\operatorname{TGA}_{(++)}{ }^{\mathrm{a}}$ & 2 & 2,9 & 2 & 5,6 & 0 & 0,0 \\
\hline TOF & 2 & 2,9 & 2 & 5,6 & 0 & 0,0 \\
\hline CCTGA+VSD+coa & 1 & 1,4 & 1 & 2,8 & 0 & 0,0 \\
\hline TA & 1 & 1,4 & 0 & 0,0 & 1 & 3,0 \\
\hline TA+PA & 1 & 1,4 & 0 & 0,0 & 1 & 3,0 \\
\hline Truncus & 1 & 1,4 & 1 & 2,8 & 0 & 0,0 \\
\hline VSD & 1 & 1,4 & 1 & 2,8 & 0 & 0,0 \\
\hline
\end{tabular}

${ }^{a} \mathrm{TGA}(++)=\mathrm{TGA}+\mathrm{VSD}+1$ other $\operatorname{defect}(\mathrm{CoA} \times 1$, and $\mathrm{PS} \times 1)$.

Table 2: CCHDs diagnosed late, after discharge home.

\begin{tabular}{|c|c|c|}
\hline Heart defect & Number $(n=19)$ & $\%$ \\
\hline CoA/IAA & 6 & 31.6 \\
\hline CoA & 4 & 21.1 \\
\hline $\mathrm{COA}+\mathrm{VSD}$ & 1 & 5.3 \\
\hline IAA+VSD & 1 & 5.3 \\
\hline ALCAPA & 2 & 10.5 \\
\hline PDA & 2 & 10.5 \\
\hline AVSD & 1 & 5.3 \\
\hline DORV+VSD & 1 & 5.3 \\
\hline MS & 1 & 5.3 \\
\hline PbrS & 1 & 5.3 \\
\hline SV & 1 & 5.3 \\
\hline TGA(++) ${ }^{a}$ & 1 & 5.3 \\
\hline TOF & 1 & 5.3 \\
\hline Double aortic arch & 1 & 5.3 \\
\hline VSD & 1 & 5.3 \\
\hline
\end{tabular}

to be diagnosed late was CoA, in 6 of the 19 children who were diagnosed after discharge home. Three of them were critically ill at diagnosis or in a state of circulatory shock. There was no significant difference in the number of late diagnosis between 5 -year periods of the study.

The most common CCHDs in the total cohort were CoA (32/188), VSD (24/188) and HLHS (21/188). An overview of all diagnosis is shown in table 3.

Of the 155 live born children 20 had genetic diagnosis. The most common were trisomy 21 (9), XO (2) and microdeletion of chromsome 22 (2). Among the 36 terminated pregnancies two fetuses had trisomy 21 , two trisomy 13 , and further two other chromosomal abnormalities. 


\begin{tabular}{|c|c|c|}
\hline Heart defect & Number $(n=188)$ & $\%$ \\
\hline CoA & 32 & 17,0 \\
\hline CoA & 19 & 10,1 \\
\hline $\mathrm{CoA}+\mathrm{VSD}$ & 8 & 4,3 \\
\hline$I A A+V S D$ & 2 & 1,1 \\
\hline CoAtas & 1 & 0,5 \\
\hline CoAtsubas & 1 & 0,5 \\
\hline CoA+subas+VSD & 1 & 0,5 \\
\hline VSD & 24 & 12,8 \\
\hline HLHS & 21 & 11,2 \\
\hline TGA & 21 & 11,2 \\
\hline TGA & 12 & 6,4 \\
\hline TGA+VSD & 3 & 1,6 \\
\hline $\operatorname{TGA}(++)^{a}$ & 6 & 3,2 \\
\hline TOF & 13 & 6,9 \\
\hline Complicated & 12 & 6,4 \\
\hline AVSD & 9 & 4,8 \\
\hline PS & 8 & 4,3 \\
\hline AS & 8 & 4,3 \\
\hline AS & 6 & 3,2 \\
\hline AS+coa & 2 & 1,1 \\
\hline PA/IVS & 6 & 3,2 \\
\hline PA/VSD & 6 & 3,2 \\
\hline Truncus & 5 & 2,7 \\
\hline Truncus & 4 & 2,1 \\
\hline Truncus+IAA & 1 & 0,5 \\
\hline sv & 4 & 2,1 \\
\hline DORV & 4 & 2,1 \\
\hline ALCAPA & 2 & 1,1 \\
\hline Ebstein & 2 & 1,1 \\
\hline PDA & 2 & 1,1 \\
\hline APW & 1 & 0,5 \\
\hline CCTGA+VSD+coa & 1 & 0,5 \\
\hline Coronary fistula & 1 & 0,5 \\
\hline Ductal aneurysm & 1 & 0,5 \\
\hline MS & 1 & 0,5 \\
\hline Pbrs & 1 & 0,5 \\
\hline TA & 1 & 0,5 \\
\hline TA+PA & 1 & 0,5 \\
\hline Double aortic arch & 1 & 0,5 \\
\hline
\end{tabular}

Of 155 live born children with CCHD 5 children could not be offered operation or intervention either due to the severity of the CCHD, serious chromosomal defects, prematurity or neurological problems and all 5 died. Of the remaining 150 children, 117 had surgery performed, and 33 interventional heart catheterisation, all before the age of 1 year. The surgeries and interventional heart catheterisations were performed in Iceland, Boston (USA), Lund (Sweden), or London (UK).

At the end of the follow-up period 141 of 150 children who were eligible for surgical or interventional treatment are alive (94\%), at the age of 4-19 years. Nine children died after surgical or interventional treatment for CCHD was performed. Of those two children $1.3 \%$ ) died within 30 days after the procedure. One died after interventional ballon dilatation of valvular pulmonary stenosis, and one after surgical atrial septectomy and Blalock Taussig shunt procedure for pulmonary atresia with intact ventricular septum. Three children died of multiple problems caused by genetic disorders. Two children died of late complications of complex CCHD. Further two children died of other or unknown causes not related to their CCHD.

\section{Discussion}

This nationwide study covers a 15-year period and illustrates the incidence, timing of diagnosis and results of treatment of CCHDs. The incidence of 2.33/1,000 live born is similar to the incidence of 1.9-2.6/1000 found in previous studies that also include CCHDs requiring intervention in the first year of life [4-6]. The observed decrease in incidence during the study period might be related to the implementation of a nationwide but optional first trimester screening for chromosomal abnormalities in the year 2003. This program has led to increased early detection and abortion of foetuses with serious chromosomal defects such as Down syndrome where CCHDs are common [19,20].

Prenatal diagnosis was made in $37 \%$ of the total cohort. Almost half of those diagnosed prenatally had so serious CCHD that abortion was chosen. The remaining CCHDs diagnosed prenatally composed $23 \%$ of live born children with CCHD. The proportion of prenatal diagnosis is similar to many previous studies, but recent studies are increasingly showing higher proportions of prenatal diagnosis, or 50\%-75\% [17,21,22]. Our results in prenatal diagnosis of very severe CCHDs such as HLHS with poor prognosis are good. There is however room for improvement in prenatal diagnosis of CCHDs that are serious but seldom lead to abortion, such as TGA, where no prenatal detection was achieved during the study period. During the study period systematic examination of the outflow tracts and three vessel view was not performed at screening foetal ultrasound. Implementation of these techniques would be necessary in order to improve our results of prenatal screening for CCHDs [23].

As the majority of children with CCHD are not diagnosed prenatally it is important to organize effective methods to detect children with CCHD early, before they show serious symptoms. During the study period newborn children were examined twice at the age of 1 and 5 days. POX screening was not performed. By these means only $12.3 \%$ of live born children with CCHD were diagnosed late, after discharge home.

Some of the late diagnosed CCHDs (shown in table 2) are very difficult to detect early, such as ALCAPA and double aortic arch. Late diagnosis of other CCHDs could probably be reduced with methods such as POX. At least 3 children with cyanotic heart disease in our material probably would have been diagnosed earlier if POX had been applied. If these diagnosis had been detected early, the proportion of late diagnosis would have been reduced to $10,3 \%$, which compares well with previous studies showing very few late diagnosis [16]. 
The most common late diagnosis in our study was CoA, where late diagnosis is a universal problem with or without POX screening $[4,7,8,14,15]$. The number of CoA in the total cohort was 32 and $6(18.8 \%)$ of those were diagnosed late. While more than $80 \%$ of $\mathrm{CoA}$ in our study were diagnosed prenatally or shortly after birth the fact that half of the children ( 3 of 6 ) with late diagnosis of CoA were critically ill and in a state of circulatory shock highlights the importance of trying to identify these children early.

The impact of CCHDs on survival is clear from our study. Of 188 pre- and postnatal diagnosis of CCHD 47 have led to termination of pregnancy or death (25\%). CCHDs with poor prognosis such as HLHS where two chamber correction is not possible account for the majority of those. The survival of those that were offered surgery or catheter intervention is however acceptable. In-hospital mortality was $1.3 \%$ which compares favourably with previous studies [24,25]. Later mortality after surgery or intervention occurred in 7 of 148 children, but the majority of those could be explained by serious comorbidities, and only two directly to the CCHD.

\section{Conclusion}

The organisation of pre- and postnatal diagnosis of CCHDs in Iceland during the period of 2000-2014 resulted in a high proportion of children with very serious CCHD and poor prognosis to be detected prenatally. The children with CCHD not diagnosed prenatally were most commonly diagnosed early after birth, and late diagnosis after discharge home from birth facility were relatively few. Late diagnosis of CCHD did not result in any deaths. The results of pre- and postnatal detection of CCHDs can be improved by refining the methods for prenatal foetal echocardiography and by adding POX screening of newborns. Both changes have been implemented, and the decisions were supported by the data presented.

\section{References}

1. van der Linde $D$, Konings $E E$, Slager $M A$, Witsenburg $M$, Helbing WA, et al Birth Prevalence of Congenital Heart Disease Worldwide: A Systematic Review and Meta-Analysis. J Am Coll Cardiol. 2011; 58: 2241-2247. PubMed: https://www.ncbi.nlm.nih.gov/pubmed/22078432

2. Leirgul E, Fomina $T$, Brodwall $K$, Greve $G$, Holmstrøm $H$, et al. Birth prevalence of congenital heart defects in Norway 1994-2009-A nationwide study. Am Heart J. 2014; 168: 956-964.

PubMed: https://www.ncbi.nlm.nih.gov/pubmed/25458661

3. Stephensen SS, et al. Nýgengi og greining meðfæddra hjartagalla á Íslandi 1990-1999. Læknablaðið. 2002; 88: 281-287.

4. Ewer AK, Middleton LJ, Furmston AT, Bhoyar A, Daniels JP, et al. Pulse oximetry screening for congenital heart defects in newborn infants (Pulse0x): a test accuracy study. Lancet. 2011; 378: 785-794. PubMed: https://www.ncbi.nlm.nih.gov/pubmed/21820732

5. Dawson AL, Cassell CH, Riehle-Colarusso T, Grosse SD, Tanner JP, et al. Factors Associated With Late Detection of Critical Congenital Heart Disease in Newborns. Pediatrics. 2013; 132: E604-E611.

PubMed: https://www.ncbi.nlm.nih.gov/pubmed/23940249
6. Liberman RF, Getz KD, Lin AE, Higgins CA, Sekhavat S, et al. Delayed Diagnosis of Critical Congenital Heart Defects: Trends and Associated Factors. Pediatrics. 2014; 134: E373-E381.

PubMed: https://www.ncbi.nlm.nih.gov/pubmed/25070301

7. Wren C, Reinhardt Z, Khawaja K. Twenty-year trends in diagnosis of life threatening neonatal cardiovascular malformations. Arch Dis Child Fetal Neonatal Ed. 2008; 93: F33-F35.

PubMed: https://www.ncbi.nlm.nih.gov/pubmed/17556383

8. Mouledoux JH, Walsh WF. Evaluating the Diagnostic Gap: Statewide Incidence of Undiagnosed Critical Congenital Heart Disease Before Newborn Screening With Pulse Oximetry. Pediatr Cardiol. 2013; 34: 1680-1686.

PubMed: https://www.ncbi.nlm.nih.gov/pubmed/23595939

9. Brown KL, Ridout DA, Hoskote A, Verhulst L, Ricci M, et al. Delayed diagnosis of congenital heart disease worsens preoperative condition and outcome of surgery in neonates. Heart. 2006; 92: 1298-1302.

PubMed: https://www.ncbi.nlm.nih.gov/pubmed/16449514

10. Bonnet D, Coltri A, Butera G, Fermont L, Le Bidois J, et al. Detection of transposition of the great arteries in fetuses reduces neonatal morbidity and mortality. Circulation. 1999; 99: 916-918.

PubMed: https://www.ncbi.nlm.nih.gov/pubmed/10027815

11. Calderon J, Angeard $\mathrm{N}$, Moutier S, Plumet $\mathrm{MH}$, Jambaqué $\mathrm{I}$, et al. Impact of Prenatal Diagnosis on Neurocognitive Outcomes in Children with Transposition of the Great Arteries. J Pediatr. 2012; 161: 94-98. PubMed: https://www.ncbi.nlm.nih.gov/pubmed/22284567

12. van Velzen $C L$, Haak MC, Reijnders G, Rijlaarsdam ME, Bax CJ, et al. Prenatal detection of transposition of the great arteries reduces mortality and morbidity. Ultrasound Obstet Gynecol. 2015; 45: 320-325. PubMed: https://www.ncbi.nlm.nih.gov/pubmed/25297053

13. Mellander $M$, Sunnegardh J. Failure to diagnose critical heart malformations in newborns before discharge--an increasing problem? Acta Paediatr. 2006; 95: 407-413.

PubMed: https://www.ncbi.nlm.nih.gov/pubmed/16720486

14. Peterson C, Ailes E, Riehle-Colarusso T, Oster ME, Olney RS, et al. Late Detection of Critical Congenital Heart Disease among US Infants Estimation of the Potential Impact of Proposed Universal Screening Using Pulse Oximetry. Jama Pediatrics. 2014; 168: 361-370. PubMed: https://www.ncbi.nlm.nih.gov/pubmed/24493342

15. de-Wahl Granelli A, Wennergren M, Sandberg K, Mellander M, Bejlum C, et al. Impact of pulse oximetry screening on the detection of duct dependent congenital heart disease: a Swedish prospective screening study in 39,821 newborns. BMJ. 2009; 338: 3037.

PubMed: https://www.ncbi.nlm.nih.gov/pubmed/19131383

16. Thangaratinam S, Brown K, Zamora J, Khan KS, Ewer AK. Pulse oximetry screening for critical congenital heart defects in asymptomatic newborn babies: a systematic review and meta-analysis. Lancet. 2012; 379: 2459-2464.

PubMed: https://www.ncbi.nlm.nih.gov/pubmed/22554860

17. Riede FT, Wörner C, Dähnert I, Möckel A, Kostelka M, et al. Effectiveness of neonatal pulse oximetry screening for detection of critical congenital heart disease in daily clinical routine-results from a prospective multicenter study. Eur J Pediatr. 2010; 169: 975-981. PubMed: https://www.ncbi.nlm.nih.gov/pubmed/20195633

18. Meberg A, Andreassen A, Brunvand L, Markestad T, Moster D, et al. Pulse oximetry screening as a complementary strategy to detect critical congenital heart defects. Acta Paediatr. 2009; 98: 682-686. PubMed: https://www.ncbi.nlm.nih.gov/pubmed/19154526

19. Freeman SB, Taft LF, Dooley KJ, Allran K, Sherman SL, et al. Populationbased study of congenital heart defects in Down syndrome. Am J Med Genet. 1998; 80: 213-217.

PubMed: https://www.ncbi.nlm.nih.gov/pubmed/9843040 
20. Irving CA, Chaudhari MP. Cardiovascular abnormalities in Down's syndrome: spectrum, management and survival over 22 years. Arch Dis Child. 2012; 97: 326-330.

PubMed: https://www.ncbi.nlm.nih.gov/pubmed/21835834

21. Carvalho JS, Allan LD, Chaoui R, Copel JA, DeVore GR, et al. ISUOG Practice Guidelines (updated): sonographic screening examination of the fetal heart. Ultrasound Obstet Gynecol. 2013; 41: 348-359.

PubMed: https://www.ncbi.nlm.nih.gov/pubmed/23460196

22. Chew C, Halliday JL, Riley MM, Penny DJ. Population-based study of antenatal detection of congenital heart disease by ultrasound examination. Ultrasound Obstet Gynecol. 2007; 29: 619-624.

PubMed: https://www.ncbi.nlm.nih.gov/pubmed/17523161
23. Carvalho JS, Mavrides E, Shinebourne EA, Campbell S, Thilaganathan B. Improving the effectiveness of routine prenatal screening for major congenital heart defects. Heart. 2002; 88: 387-391.

PubMed: https://www.ncbi.nlm.nih.gov/pubmed/12231598

24. Hoashi T, Miyata H, Murakami A, Hirata Y, Hirose $K$, et al. The current trends of mortality following congenital heart surgery: the Japan Congenital Cardiovascular Surgery Database. Interact Cardiovasc Thorac Surg. 2015; 21: 151-156.

PubMed: https://www.ncbi.nlm.nih.gov/pubmed/25924867

25. Rogers L, Brown KL, Franklin RC, Ambler G, Anderson D, et al. Improving Risk Adjustment for Mortality After Pediatric Cardiac Surgery: The UK PRAiS2 Model. Ann Thorac Surg. 2017; 104: 211-219.

PubMed: https://www.ncbi.nlm.nih.gov/pubmed/28318513 